\title{
Unresectable Malignant Liver Neoplasm
}

National Cancer Institute

\section{Source}

National Cancer Institute. Unresectable Malignant Liver Neoplasm. NCI Thesaurus. Code C35648.

A malignant neoplasm that affects the liver and it is not amenable to surgical resection. 